In press: International Journal of Primatology

\title{
Seasonal Effects on Reconciliation in Macaca fuscata yakui
}

\section{Bonaventura Majolo ${ }^{1,2}$ and Nicola Koyama ${ }^{1}$}

${ }^{1}$ School of Biological and Earth Sciences, Liverpool John Moores University, Byrom St., Liverpool, L3 3AF, England.

${ }^{2}$ Corresponding author: Phone number: +39-06-44202526. E-mail:

raffiebino@inwind.it

Address for correspondence:

via di Santa Costanza, 21

00198 Rome

Italy 


\begin{abstract}
Diet composition may have profound effects on the activity budgets, level of food competition, and social behaviour of a species. Similarly, in seasonally breeding species, the mating season represents a period where the competition for mating partners increases, thus affecting amicable social interactions among group members. The aims of this study were thus to analyse the importance of the mating season and of seasonal variations in diet composition and food competition on reconciliation in wild female Japanese macaques (Macaca fuscata yakui) living on Yakushima Island, Japan. Yakushima macaques are appropriate for this topic as they are seasonal breeders and their diet composition significantly changes among the seasons. Although large differences were found between the summer months and the winter and early spring months in activity budgets and the consumption of the main food sources (i.e. fruits, seeds and leaves), the level of food competition and conciliatory tendency remained unaffected. Conversely, conciliatory tendency was significantly lower during the mating season than in the non-mating season. Moreover, conciliatory tendency was lower when one or both female opponents were in oestrous than when they were not. These results indicate that the mating season have profound effects on reconciliation whereas this is not true for seasonal changes in activity budgets and diet composition. The detrimental effects of the mating season on female social relationships and reconciliation may be due to the importance of female competition for access to male partners in multi-male, multi-female societies.
\end{abstract}

Key Words: Diet, competition, Japanese macaque, mating season, post-conflict behaviour. 


\section{INTRODUCTION}

Social primates usually concentrate their activity during daylight and devote a significant proportion of the day to the exchange of amicable social behaviour (mainly grooming). Grooming helps primates to establish and maintain long-lasting good relationships with some other group members which have consequences on an animal's fitness (e.g. increased tolerance or agonistic support; Dunbar, 1991). Animals who maintain amicable relationships with one another also have a higher frequency of reconciled conflicts than animals who rarely exchange grooming or have competitive relationships (the good relationship hypothesis; Aureli et al., 2002). Reconciliation is defined as the post-conflict friendly reunion of former opponents that restores their social relationship (Aureli \& de Waal, 2000). Given that grooming is time consuming, the possibility for an animal to maintain amicable relationships and a high frequency of reconciliation with some group companions clearly depends on how much time is left from more essential activities (e.g. foraging or mating; Dunbar 1992). Moreover, ecological variables that may influence the type of social relationships among group members (e.g. Krebs and Davies, 1997) are also expected to have an effect on reconciliation. When food is less available and/or clumped, for example, animals should spend more time searching for it and should have less time for grooming exchange (e.g. Miller \& Dietz 2004). Under these circumstances, contest food competition among group members should be high and, consequently, the overall frequency of reconciliation should be low. Diet composition also determines activity budgets and social relationships among group members. Frugivorous species fulfil their daily energetic requirement quicker than folivores (as fruits and seed are more energetic food sources than leaves) and thus usually have more time available for social behaviour (Gillespie \& Chapman 2001; Janson and Goldsmith, 1995). At the same time, however, 
and other things being equal (e.g. food availability), food competition is expected to be higher in frugivorous species than in folivores (van Schaik 1989). This is because fruits and seeds often occur in more clumped, potentially monopolisable, patches than leaves (Pruetz \& Isbell 2000), and they constitute more valuable resources (Janson \& Goldsmith 1995).

The mating season represents another possible source of competition, as animals strive to maximise their reproductive success. Although female-female competition for mating partners has often been neglected, this may be an important factor affecting female social relationships. This is particularly true for species living in multi-male, multi-female groups and characterised by multiple copulations usually concentrated within the consorting period, as is the case in macaques (Melnick \& Pearl, 1987). This type of sexual behaviour is time consuming so that dominant males may be unable to monopolise mating partners, particularly when two or more females are in oestrus at the same time (Vasey, 1998). Moreover, females consorting with dominant males may gain many sort- or long-term benefits, such as reduced aggression for her and her infant from the other group members or preferential access to food sources during the consortship (Palombit et al., 1997). All these factors are likely to favour female mate choice and female-female competition for mating partners (Small, 1990; Vasey, 1998). Indeed, there is some evidence that the mating season deteriorates female social relationships and increases competition among females (D’Amato et al., 1982; Mehlman \& Chapais, 1988).

Under high competitive regimes, strict dominant hierarchies and rank-related differences in access to valuable resources are likely to evolve (Saito 1996; Whitten 1988). In this context, group members are either friends or competitors so that animals particularly benefit by exchanging grooming with only some partners (i.e. close-kin 
and/or high-ranking animals) while ignoring the others (Dunbar, 1991; Janson 1988). Studies mainly conducted on macaques support this picture (Thierry, 2000). Despotic species (e.g. Japanese and rhesus macaques) are characterised by high levels of competition that result in steep hierarchies, grooming biased towards close-kin and/or high-ranking animals, and low frequency of reconciliation with the average group member (Matsumura, 1996; Sterck et al., 1997). Egalitarian species (e.g. crested macaques), conversely, have low competitive regimes and relaxed hierarchies, grooming is not significantly biased towards some animals and the average frequency of reconciliation is high.

Behavioural ecologists have usually concentrated their attention on how habitat characteristics and competitive regimes determine differences in social behaviour among species or populations (Henzi \& Barrett, 2003). Conversely, short-term changes in the level of competition have rarely been analysed, although these may be particularly important for species breeding seasonally, or for those affording large variations in food abundance during the year. This lack of data also applies to studies on reconciliation and it is probably related to the scarcity of studies on this topic on wild animals (Aureli \& de Waal, 2000). This study thus aimed to analyse if and how shortterm changes in the level of competition affect frequency of reconciliation among female Japanese macaques (Macaca fuscata yakui). The Japanese macaques living on Yakushima island are seasonal breeders and present large variations in their diet composition. During the summer months Yakushima macaques consume more fruits and seeds than in the winter and early spring months, while the reverse is true for the consumption of leaves (Hanya et al. 2003; Hill 1997). Moreover, fruit- and seed-tree species are more clumped than leaf-tree species in Yakushima (Agetsuma, 1995). We thus predict that activity budgets should significantly vary during the year. Moreover, 
contest food competition should be greater the higher the consumption of fruits and seeds is. Based on these predictions, we tested four different hypotheses: 1) Frequency of reconciliation should be lower the greater the level of contest food competition is; 2) Frequency of reconciliation should be lower during the mating season than during the non-mating season; 3) Frequency of reconciliation should be higher between animals exchanging grooming (i.e. friends) than between animals not exchanging grooming (i.e. non-friends); and 4) Frequency of reconciliation among female friends should increase, or at least remain stable, when the level of competition increases (as social partners are particularly important under high competition) while the reverse should be true for reconciliation among female non-friends. To avoid confounding the effect of food competition and of the mating season on reconciliation, these two effects were analysed separately. First, we analysed the effect of seasonal changes in food competition on reconciliation within the non-mating season. Second, we determined whether the level of food competition differed between the mating and the non-mating season. In case no difference between these two periods was evident, we could reliably determine the importance of the mating season on the frequency of reconciliation.

\section{METHODS}

\section{Study Area and Subjects}

Yakushima is a volcanic island of around $500 \mathrm{~km}^{2}$ located $60 \mathrm{~km}$ south of Kyushu, Japan $\left(31^{\circ} \mathrm{N}, 131^{\circ} \mathrm{E}\right)$. The island is covered with a warm sub-tropical evergreen forest on the coast (where the study area was), approximately up to $500 \mathrm{~m}$ a.s.l. (Agetsuma $\&$ Nakagawa 1998). Temperature ranges from a minimum of about $3^{\circ} \mathrm{C}$ to a maximum of about $32^{\circ} \mathrm{C}$, rainfall is between 100 and $400 \mathrm{~mm}$ each month but it is higher than 400 
mm in June, which is the peak of the rainy season (Hill, 1997). No natural predators are present on the island (Maruhashi et al. 1998).

Subjects of this study were eight females (age $\geq 4$ years) living in Nina A group. At the beginning of the study (June 2001) the group consisted of 13 sub-adult/adult males, 3 yearlings, 1 infant, plus the 8 females. Seven males (i.e. 6 sub-adult and 1 adult) emigrated from the study group during October 2001.

\section{Data Collection}

Data were collected from June $13^{\text {th }} 2001$ to April $30^{\text {th }} 2002$ with only one interruption from December $20^{\text {th }} 2001$ to January $15^{\text {th }} 2002$. Data on activity budgets (i.e. foraging, moving, grooming, or resting) and on the consumption of the two main food categories (i.e. fruits and seeds or leaves) were collected using focal animal sampling (each observation session lasting 10 minutes; Altmann, 1974). Data were collected from 7.00 to 19.00 , approximately evenly on each study animal to avoid biasing the sample. Preliminary data showed that conflicts over food were too rare within focal observations to allow statistical analyses. We thus collected ad libitum data on aggressive interactions over food. Data on post-conflict behaviour were collected using the post-conflict-matched-control (PC-MC) method (de Waal and Yoshihara, 1983). Post-conflict sessions started within 30 seconds after an agonistic interaction between two or more females, on the victim or the aggressor, lasting 5 minutes. For each aggressive interaction, the identity of the animals involved, the intensity of the attack (i.e. threat, chase, slap, or bite), the context of conflict (i.e. foraging or groomingresting) were recorded. Time elapsed (seconds) from the end of the conflict to the first affiliative interaction (i.e. grooming, lip-smacking, muzzle contact) between former opponents was recorded. On the next possible day, a matched-control observation was 
made on the same animal and using the same sampling method. The session was postponed for at least 10 minutes if the focal animal was involved in an agonistic interaction within 3 minutes before a planned MC (Aureli et al., 1993). The session only started when the context was similar to that of the PC and the other females involved in the conflict were visible. If these conditions were not met within 2 weeks, the PC was discarded.

\section{Data Analysis}

Data on activity budgets and diet composition are presented as percentage of time spent in each activity by the females. For each day, the number of conflicts over food was divided by the hours of contact with the monkeys to obtain frequencies per hour per day. This figure was considered a reliable measure of the level of contest food competition among females (Isbell, 1991).

Reconciliation was never observed following conflicts over food (Majolo, 2004), supporting the findings of previous studies (e.g. Aureli, 1992; Koyama, 2001; Verbeek and de Waal, 1997). Therefore, we decided to not include conflicts over food when calculating conciliatory tendency (see below) but to analyse the level of contest food competition separately. We note here, however, that adding conflicts over food to the analyses on conciliatory tendency did not alter our results.

Each PC-MC pair was assigned to one of the following three groups according to the timing of the first affiliative interaction between former opponents in the two observation sessions: 1) “Attracted” pair: affiliative interaction between former opponents was observed earlier in the PC than in the MC, or only in the PC; 2) “Dispersed” pair: affiliative interaction between former opponents was observed later in the PC than in the MC, or only in the MC; 3) "Neutral” pair: affiliative interaction 
between former opponents was observed at the same time in the PC and the MC, or was never observed in the two sessions. Conciliatory tendency per female was measured following the formula (Veenema et al., 1994):

$$
\begin{aligned}
& \text { (Number of “attracted” pairs - Number of “dispersed” pairs) / } \\
& \text { Total number of pairs }
\end{aligned}
$$

The mating season (defined as the period between the first and last recorded consortship in which sexual mounts were observed; Hanby and Brown, 1974) began on $28^{\text {th }}$ August and was finished by the time the data collection began again in January 2002 (see above). First, we analysed the effect of food competition on reconciliation. We thus compared data collected in the period June-August the $27^{\text {th }}$ (hereafter, JuneAugust for the sake of simplicity), when consumption of fruits and seeds was expected to be highest and that of leaves lowest (resulting in a high level of contest food competition), with data collected in January-April, where the reverse trend was expected. Second, data collected in these two periods were pooled together, as they represented the non-mating season, and compared with data collected in the period September-December, which represented the mating season. To analyse the effect of the type of social relationship between former opponents on their conciliatory tendency we divided the PC-MC pairs for each female in two groups: conflicts between friends were those where the opponents were observed exchanging grooming during the study whereas conflicts between non-friends were those where the opponents were never observed exchanging grooming. Data on activity budgets, diet composition and conciliatory tendency were compared between the periods at the individual level using a series of Wilcoxon matched-pairs signed-rank tests. Mann-Whitney test was used to compare the daily level of contest food competition in the selected study periods. 


\section{RESULTS}

At the end of the study period, a total of 204.9 hrs of focal observation were collected, 51.2 hrs in June-August (6.4 \pm 0.2 mean hrs of observation per female \pm SE), 67.2 hrs in January-April (8.4 \pm 0.2 hrs per female), and 86.5 hrs (10.8 \pm 0.2 hrs per female) in the mating season. A total of 312 PC-MC pairs was collected: 95 in JuneAugust $(11.9 \pm 2.0$ mean number of PC-MC pairs per female \pm SE), $52(6.5 \pm 1.2$ PCMC pairs per female) in January-April, and 156 (19.5 \pm 4.9 PC-MC pairs per female) during the mating season. All the conflicts had a clear-cut result but two, in the period January-April, when neither of the opponents showed any sign of submission. Only 4 conflicts, occurring in June-August, involved more than two females while all the other conflicts were dyadic. Victims of aggression were the subjects of further aggression from the former opponents in only 7 PC observations (i.e. 7.4\%) occurring in the period June-August, in 1 PC (i.e. 1.2\%) during January-April, and in 12 PCs (i.e. 7.7\%) during the mating season. During PC observations victims were rarely observed to be aggressive towards group members other than the former opponents: redirection was observed in 3 PCs (i.e. 3.2\%) in June-August, in 2 PCs (i.e. 3.8\%) in January-April, and in 4 PCs (i.e. 2.6\%) in the mating season. Given the rarity of these events, no statistical analyses could be run on seasonal variations in alliance formation, agonistic support, further aggression from the former opponent, and redirection.

\section{The Effect of Seasonal Changes of Activity Budgets, Diet Composition and Food Competition on Reconciliation}

Monkeys spent significantly less time foraging or moving in the period June-August than in the period February-April (foraging: $\mathrm{T}=36.0, \mathrm{~N}=8, \mathrm{p}<0.01$; moving: $\mathrm{T}=37$, $\mathrm{N}=8, \mathrm{p}<0.01$; see Figure 1). Conversely, time spent grooming was greater in June- 
August than in February-April $(\mathrm{T}=37.0, \mathrm{~N}=8, \mathrm{p}<0.01$; see Figure 1). Time spent resting did not significantly differ between the two periods ( $T=20, N=8$, NS; see Figure 1). As expected, the two periods also significantly differed in the consumption of the main food categories. Monkeys spent more time foraging on fruits and seeds, and less time foraging on leaves in June-August than in February-April (time spent foraging on fruits and seeds: $\mathrm{T}=35.0, \mathrm{~N}=8, \mathrm{p}<0.01$; time spent foraging on leaves: $\mathrm{T}=36.0$, $\mathrm{N}=8, \mathrm{p}<0.01$; see Figure 1). However, contrary to our first prediction (see above) frequency of conflicts over food did not significantly differ between the two periods (June-August: $0.4 \pm 0.1$ events/hr \pm SE; January-April: $0.1 \pm 0.2$ events/hr \pm SE; U = 520.0, $\left.\mathrm{N}_{1}=32, \mathrm{~N}_{2}=37, \mathrm{NS}\right)$.

Conciliatory tendency did not differ when the periods June-August and JanuaryApril were compared ( $\mathrm{T}=12.0, \mathrm{~N}=6$, NS; see Figure 2). Conciliatory tendency was compared between the two periods according to the type of social relationship between former opponents (i.e. friends or non-friends; see above). No difference was found for conciliatory tendency between friends in the two periods (June-August: $0.2 \pm 0.1$ mean conciliatory tendency \pm SE; January-April: $0.3 \pm 0.1$ mean conciliatory tendency \pm SE; $\mathrm{T}=19.0, \mathrm{~N}=8$, NS). A similar not significant result was found when conciliatory tendency between non-friends was compared between the two periods (June-August: $0.1 \pm 0.1$ mean conciliatory tendency \pm SE; January-April: $0.1 \pm 0.2$ mean conciliatory tendency \pm SE; $T=3.5, \mathrm{~N}=8$, NS). Conciliatory tendency, however, did also not significantly differ between friends and non-friends in June-August (friends: $0.2 \pm 0.1$ mean conciliatory tendency \pm SE; non-friends: $0.1 \pm 0.1$ mean conciliatory tendency \pm $\mathrm{SE} ; \mathrm{T}=8.0, \mathrm{~N}=8, \mathrm{NS}$ ) and in January-April (friends: $0.3 \pm 0.1$ mean conciliatory tendency \pm SE; non-friends: $0.1 \pm 0.2$ mean conciliatory tendency $\pm \mathrm{SE} ; \mathrm{T}=14.0, \mathrm{~N}=$ 8, NS). 


\section{The Effect of the Mating Season on Reconciliation}

Time spent foraging was greater during the mating season than during the nonmating season $(\mathrm{T}=36.0, \mathrm{~N}=8, \mathrm{p}<0.01$; see Figure 3 ). On the contrary, both time spent moving or resting were greater during the non-mating season than in the mating season (time spent moving: $\mathrm{T}=28.0, \mathrm{~N}=8, \mathrm{p}<0.01$; time spent resting: $\mathrm{T}=20.0, \mathrm{~N}=$ 8, $\mathrm{p}<0.05$; see Figure 3). Time spent grooming did not significantly differed between the two periods ( $\mathrm{T}=9.0, \mathrm{~N}=8$, NS; see Figure 3). Monkeys spent a similar amount of time foraging on fruits or seeds $(\mathrm{T}=19.0, \mathrm{~N}=8, \mathrm{p}<0.05$; see Figure 3). However, time spent foraging on leaves was lower during the mating season than during the nonmating season $(T=36.0, N=8, p<0.01$; see Figure 3). Mostly important, frequency of conflicts over food was similar in the two periods (mating season: $0.1 \pm 0.2$ events/hr \pm SE; non-mating season: $0.1 \pm 0.1$ events/hr $\pm \mathrm{SE}$; $\mathrm{U}=1713.5, \mathrm{~N}_{1}=51, \mathrm{~N}_{2}=69$, NS). As such, the effect of the mating season on reconciliation could be properly tested excluding food competition as a possible confounding factor.

Confirming our prediction, conciliatory tendency was lower during the mating season than during the non-mating season $(T=28.0, N=8, p<0.01$; see Figure 4$)$. To test whether this result was due to female-female competition for mating partners we compared conciliatory tendency when one or both the opponents were in oestrous and when they were not, within the mating season. We decided to use female hormonal state rather than female consortship as, otherwise, we would have lost important data on how competition for mating partners affects reconciliation. This is because an oestrus female is expected to spend most of her time trying to interact and mate with adult males (Mitsunaga et al., 1992), whereas whether or not she can actually consort with a male depends on many other factors (e.g. male partner preference or availability of partners). 
Indeed, all conflicts observed when one or both the opponents were in oestrous consisted of one female aggressively displacing the other who was interacting with a male, or avoiding her from approaching a male. Confirming our previous finding, conciliatory tendency was significantly lower when one or both the opponents were in oestrous than when they were not $(T=21, N=7, p<0.01$; see Figure 4). No significant difference was found when conciliatory tendency between friends was compared between the two periods (mating season: $0.2 \pm 0.0$ mean conciliatory tendency $\pm S E$; non-mating season: $0.2 \pm 0.1$ mean conciliatory tendency $\pm \mathrm{SE} ; \mathrm{T}=20.0, \mathrm{~N}=8, \mathrm{NS}$ ). Moreover, conciliatory tendency between non-friends did not differ between the mating and the non-mating season (mating season: $-0.0 \pm 0.0$ mean conciliatory tendency $\pm \mathrm{SE}$; non-mating season: $0.1 \pm 0.1$ mean conciliatory tendency $\pm \mathrm{SE} ; \mathrm{T}=6.0, \mathrm{~N}=8, \mathrm{NS}$ ). Finally, conciliatory tendency was similar for friends and non-friends in both the mating season (friends: $0.2 \pm 0.0$ mean conciliatory tendency \pm SE; non-friends: $-0.03 \pm 0.0$ mean conciliatory tendency $\pm \mathrm{SE} ; \mathrm{T}=10.0, \mathrm{~N}=8$, NS) and the non-mating season (friends: $0.2 \pm 0.1$ mean conciliatory tendency \pm SE; non-friends: $0.1 \pm 0.1$ mean conciliatory tendency $\pm \mathrm{SE} ; \mathrm{T}=18.0, \mathrm{~N}=8$, NS).

\section{DISCUSSION}

\section{The Effect of Seasonal Changes of Activity Budgets, Diet Composition and}

\section{Food Competition on Reconciliation}

Primate socio-ecological theory predicts that habitat characteristics (e.g. food abundance and distribution) have profound effects on the activity budgets, type and level of food competition, and social relationships among group members (e.g. Janson 1988; van Schaik, 1989; Sterck et al., 1997). This pattern also becomes evident in crosspopulation studies of species inhabiting a wide range of habitats. For example, the 
observed variation in group size and composition, and in social organisation of baboons may be explained by differences in habitat characteristics (Byrne et al., 1993; Henzi \& Barrett, 2003). Although activity budgets and diet composition were significantly different in the periods June-August and January-April, these factors did not have any apparent effect on the level of food competition. The same non-significant result was obtained for conciliatory tendency. As such, we are unable to test the effect of shortterm changes in food competition on reconciliation. It is worth noticing, however, that reconciliation was unaffected by changes in activity budgets or diet composition between the two periods. This result has two not mutually exclusive explanations. First, conciliatory tendency may be relatively independent or resilient to mild and/or short seasonal changes in diet composition that affect the time available for grooming exchange. Indeed, amicable social relationships (which results in higher conciliatory tendencies) may not need to be built or maintained on a day-to-day basis in animals with a good memory, such as the Japanese macaques (van Schaik \& Deaner, 2003). Second, although significant, the differences in activity budgets and diet composition between the two periods may have been too short or of insufficient amplitude to affect social interactions and reconciliation among females. Indeed, grooming was never reduced below $20 \%$ of daily activity; still a conspicuous proportion of time in comparison to other wild groups of primates (Henzi \& Barrett, 2001). Moreover, the time spent foraging on fruits and seeds never accounted for less than $50 \%$ of total time spent foraging while time spent foraging on leaves barely exceeded $20 \%$ of time in January-April. Such observations indicate that females were never forced by ecological constraints to significantly limit the time devoted to social activities nor did they completely switch from an essentially frugivorous diet in the summer months to a 
folivorous diet in winter and early spring. This may also explain why food competition did not differ between the two periods.

\section{The Effect of the Mating Season on Reconciliation}

Confirming our prediction, this study showed that the mating season represents a period where conciliatory tendency among females is significantly reduced. The variation of conciliatory tendency under different levels of competition, however, was not affected by the type of social relationships existing between former opponents (i.e. friends or non-friends). The reduction in conciliatory tendency was particularly evident when one or both opponents are in oestrous. These findings thus indicate that female sexual activity has more detrimental effects on social relationships and reconciliation among females than seasonal changes in activity budgets or diet composition. Such a conclusion is supported by other studies showing that, in seasonally breeding primates, the mating season may greatly affect the distribution of allo-grooming among group members (D’Amato et al., 1982; Mehlman \& Chapais, 1988). This result was not unexpected if one consider the reproductive behaviour of the Japanese macaque. In this species consortships may last many days during which the male and female follow and groom each other, and often copulate with sequential mounts (Enomoto, 1974). Consortships are thus time consuming for both males and females. During the mating season females may not have much time left to interact with other females or, for lactating females, with their infants (Schino et al., 2001). Given that consortships are time consuming, receptive females normally outnumber adult males in a group, and females may receive some benefits from consorting with dominant males (e.g. protection from other aggressive individuals), female mate choice and female competition for mating partners seems to be important factors in macaque reproductive 
behaviour (Small, 1990; Takahata et al., 1994). If this is true, mating partners, exactly like food, are "resources" that cannot be shared by animals. A conflict between two females for access to an adult male during the mating season will always end with a win or lose result, other things being equal (e.g. male preference for a particular female partner). Under such circumstances, no room is left for negotiation and/or cooperation between the opponents, and so reconciliation rarely takes place. These considerations explain why reconciliation was never observed following conflicts over food in this study group (Majolo, 2004) and why conciliatory tendency was below zero when one or both the opponents were in oestrous. Previous studies have suggested that the absence of reconciliation after conflicts over food does not have long-term detrimental effects on the social relationship between former opponents (Aureli, 1992). Although our study does not address this issue, we may speculate that these detrimental effects are probably limited to the mating season. Indeed, conciliatory tendency in the period immediately following the end of the mating season (i.e. January-April) was similar to the period preceding it (i.e. June-August). If the mating season had any long-term effect on female social relationships, conciliatory tendency should have remained low in the period following it. Whether or not this is true, the mating season represented a period where the occurrence of reconciliation significantly decreased. We predict the effect of the mating season on conciliatory tendency being more evident in species or populations with lower operational sex ratios and thus greater female competition for mating partners. 


\section{ACNOWLEDGEMENTS}

The Yakushima District Forestry Office kindly gave us permission to carry on the study. We are grateful to Drs. S. Suzuki and D.S. Hill, and all the students at the Kyoto University Yakushima Station for their help during the course of the study. We would like to thank the organisers of the IPS 2004 symposium on conflict management and, in particular, Elisabetta Palagi. We thank two anonymous referees for useful comments on the manuscript. BM was funded by a Liverpool John Moores University studentship. 


\section{REFERENCES}

Agetsuma, N. (1995). Dietary selection by Yakushima macaques (Macaca fuscata yakui): the influence of food availability and temperature. Int. J. Primatol. 16(4): 611-627.

Agetsuma, N., and Nakagawa, N. (1998). Effects of habitat differences on feeding behaviors of Japanese monkeys: comparison between Yakushima and Kinkazan. Primates 39(3): 275-290.

Altmann, J. (1974). Observational study of behavior: sampling methods. Behaviour 49: 227-267.

Aureli, F. (1992). Post-conflict behaviour among wild long-tailed macaques (Macaca fascicularis). Behav. Ecol. Sociobiol. 31: 329-337.

Aureli, F., and de Waal, F.B.M. (2000). Natural Conflict Resolution. University of California Press, Berkeley.

Aureli, F., Veenema, H.C., van Panthasleon van Eck, C.J. and van Hooff, J.A.R.A.M. (1993). Reconciliation, consolation, and redirection in Japanese macaques (Macaca fuscata). Anim. Behav. 124(1-2): 1-21.

Aureli, F., Cords, M., and van Schaik, C.P. (2002). Conflict resolution following aggression in gregarious animals: a predictive framework. Anim. Behav. 64: 325-343.

Barrett, L. and Henzi, S.P. (2001). The utility of grooming in baboon troops. In Noë, R.., van Hooff, J.A.R.A.M. and Hammerstein, P. (eds.), Economics in Nature, Cambridge University Press, Cambridge, pp. 119-145. 
Byrne, R.W., Whiten, A., Henzi, S.P. and Mc Culloch, F.M. (1993). Nutritional constraints on mountain baboons (Papio ursinus): implications for baboon socioecology. Behav. Ecol. Sociobiol. 33: 233-246.

de Waal, F.B.M., and Yoshihara, D. (1983). Reconciliation and redirected affection in rhesus monkeys. Behaviour 85: 224-241.

D’Amato, F.R., Troisi, A., Scucchi, S. and Fuccillo, R. (1982). Mating season influence on allogrooming in a confined group of Japanese macaques: a quantitative analysis. Primates 23(2): 220-232.

Dunbar, R.I.M. (1991). Functional significance of social grooming in primates. Folia Primatol. 57: 121-131

Dunbar, R.I.M. (1992). Time: a hidden constraint on the behavioural ecology of baboons. Behav. Ecol. Sociobiol. 31: 35-49.

Enomoto, T. (1974). The sexual behavior of Japanese monkeys. J. Hum. Evol. 3: 351372.

Gillespie, T. R. and Chapman, C. A. 2001. Determinants of group size in the red colobus monkey (Procolobus badius): an evaluation of the generality of the ecological-constraints model. Behav. Ecol. Sociobiol. 50: 329-338.

Hanby, J.P. and Brown, C.E. (1974). The development of sociosexual behaviours in Japanese macaques Macaca fuscata. Behaviour 59: 152-196.

Hanya, G., Noma, N. and Agetsuma, N. (2003). Altitudinal and seasonal variations in the diet of Japanese macaques in Yakushima. Primates 44: 51-59.

Henzi S.P. \& Barret L. (2003). Evolutionary ecology, sexual conflict, and behavioral differentiation among baboon population. Evol. Anthropol. 12: 217-230. 
Hill, D.A. (1997). Seasonal variation in the feeding behavior and diet of Japanese macaques (Macaca fuscata yakui) in lowland forest of Yakushima. Am. J. Primatol. 43: 305-322.

Isbell, L.A. (1991). Contest and scramble competition: patterns of female aggression and ranging behavior among primates. Behav. Ecol. Sociobiol. 2(2): 143-155. Janson, C.H. (1988). Intra-specific food competition and primate social structure: a synthesis. Behaviour 105: 1-17.

Janson, C.H. and Goldsmith, M.L. (1995). Predicting group size in primates: foraging costs and predation risks. Behav. Ecol., 6(3): 326-336.

Koyama, N.F. (2001). The long-term effects of reconciliation in Japanese macaques Macaca fuscata. Ethology 107: 975-987.

Krebs, J.R. and Davies, N.B. (1997). Behavioural Ecology: an Evolutionary Approach. Blackwell Science, Oxford.

Majolo, B. (2004). Conflict Management in Wild Japanese Macaques (Macaca fuscata yakui). Unpublished Ph.D. Thesis, Liverpool John Moores University, Liverpool.

Maruhashi, T., Saito, C. and Agetsuma, N. (1998). Home range structure and intergroup competition for land of Japanese macaques in evergreen and deciduous forests. Primates 39(3): 291-301.

Matsumura, S. (1996). The evolution of “egalitarian” and “despotic” social systems among macaques. Primates 40(1): 23-31.

Mehlman, P.T. and Chapais, B. (1988). Differential effects of kinship, dominance, and the mating season on female allogrooming in a captive group of Macaca fuscata. Primates 29(2): 195-217. 
Melnick, D.J. and Pearl, M.C. (1987). Cercopithecines in multimale groups: genetic diversity and population structure. In: Smuts, B.B., Cheney, D.L., Seyfarth, R.M., Wrangham, R.W. and Struhsaker, T.T. (eds.), Primate Societies, University of Chicago Press, Chicago, pp. 121-134.

Miller, K. E. and Dietz, J. M. (2004). Fruit yield, not DBH or fruit crown volume, correlates with time spent feeding on fruits by wild Leontopithecus rosalia. Int. J. Primatol. 25(1): 27-39.

Mitsunaga, F., Nozaki, M., Inoue, M., Takenaka, A., Takenaka, O., Sakura, O., Sugyiama, Y. and Ohsawa, H. (1992). Steroid hormones and sexual behavior of female Japanese monkeys in an enclosed group. In Itoigawa, N., Sugyiama, Y., Sackett, G.P. and Thomson, R.K.R. (eds.), Topics in Primatology. 2. Behavior, Ecology, and Conservation, University of Tokyo Press, Tokyo, pp. 23-34.

Palombit, R., Seyfarth, R.M. and Cheney, D.L. (1997). The adaptive value of “friendships” to female baboons: experimental and observational evidence. Anim. Behav. 54: 599-614.

Pruetz, J.D. and Isbell, L.A. (2000). Correlations of food distribution and patch size with agonistic interactions in female vervets (Chlorocebus aethiops) and patas monkeys (Erythrocebus patas) living in simple habitats. Behav. Ecol. Sociobiol. 49: 38-47.

Saito, C. (1996). Dominance and feeding success in female Japanese macaques, Macaca fuscata: effects of food patch size and inter-patch distance. Anim. Behav., 51: 967-980.

Schino, G., Majolo, B., Ventura, R. and Troisi, A. (2001). Resumption of sexual activity affects mother-infant interactions in Japanese macaques. Behaviour 138: 261275. 
Small, M.F. (1990). Promiscuity in barbary macaques (Macac sylvanus). Am. J. Primatol. 20: 267-282.

Soltis, J., Thomsen, R. and Takenaka, O. (2001). The interaction of male and female reproductive strategies and paternity in wild Japanese macaques, Macaca fuscata. Anim. Behav. 62: 485-494.

Sterck, E.H.M., Watts, D.P. and van Schaik, C.P. (1997). The evolution of female social relationships in nonhuman primates. Behav. Ecol. Sociobiol. 41: 291-309.

Takahata, Y., Sprague, D.S., Suzuki, S. and Okayasu, N. (1994). Female competition, co-existence, and the mating structure of wild Japanese macaques on Yakushima Island, Japan. In Jarman, P.J. and Rossiter, A. (eds.), Animal Societies. Individuals, Interactions and Organisation, Kyoto University Press, Kyoto, pp. 163-179.

Thierry, B. (2000). Covariation of conflict management patterns across macaque species. In Aureli, F. and de Waal, F.B.M. (eds.), Natural Conflict Resolution, University of California Press, Berkeley, pp. 106-128.

van Schaik, C. P. (1989). The ecology of social relationships amongst female primates. In Standen, V. and Foley, R.A. (eds.), Comparative Socioecology: The Behavioral Ecology of Humans and Other Mammals, Blackwell, Oxford, pp. 195-218.

van Schaik, C.P. and Deaner, R.O. (2003). Life history and cognitive evolution in primates. In de Waal, F.B.M. and Tyack, P.L. (eds.), Animal Social Complexity, Harvard University Press, Cambridge, pp. 5-25.

Vasey, P.L. (1998) Female choice and inter-sexual competition for female sexual partners in Japanese macaques. Behaviour 135: 579-597. 
Veenema, H.C., Das, M. and Aureli, F. (1994). Methodological improvements for the study of reconciliation. Behav. Processes 31: 29-38.

Verbeek, P., and de Waal, F.B.M. (1997). Postconflict behavior of captive brown capuchins in the presence and absence of attractive food. Int. J. Primatol. 18(5): 703- 725.

Whitten, P.L. (1988). Effects of patch size quality and feeding subgroup size on feeding success in vervet monkeys (Cercopithecus aethiops). Behaviour 105: 35-52. 
Figure 1. Activity budgets and time spent foraging on the two main food sources in the periods June-August and January-April.

Figure 2. Activity budgets and time spent foraging on the two main food sources during the mating and the non-mating season.

Figure 3. Conciliatory tendency in the periods June-August and January-April.

Figure 4. Conciliatory tendency during the mating and the non-mating season and, within the mating season, when one or both the opponents were in oestrous or not. 
$\square$ June-August 圈 January-April

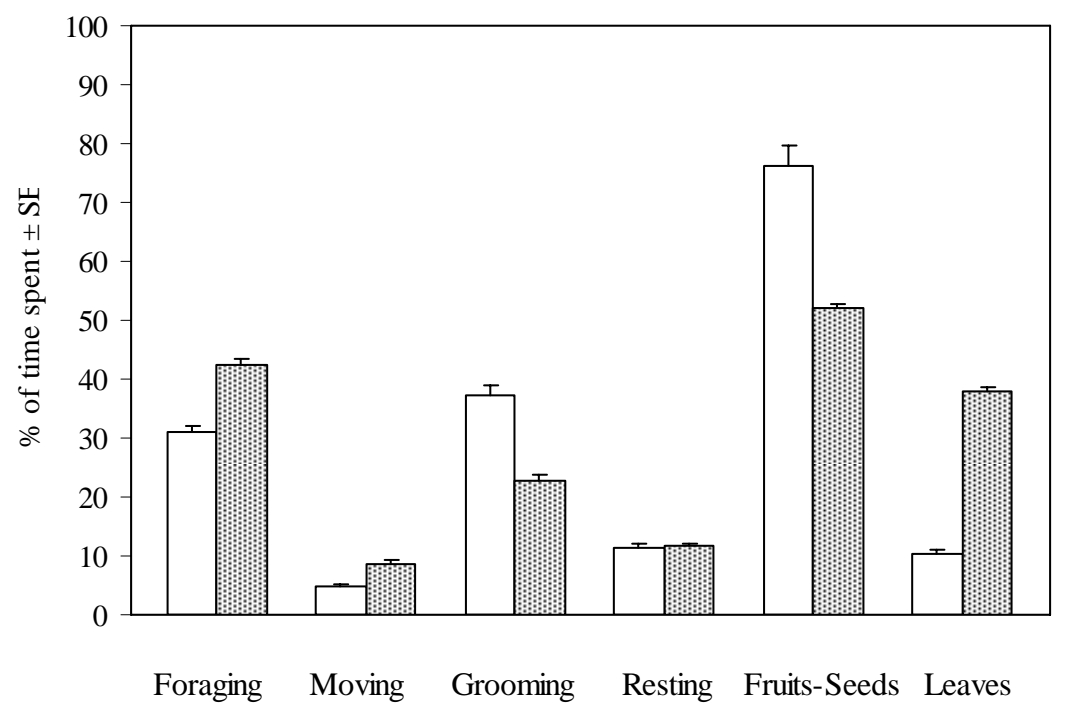


$\square$ Mating season 중 Non-mating season

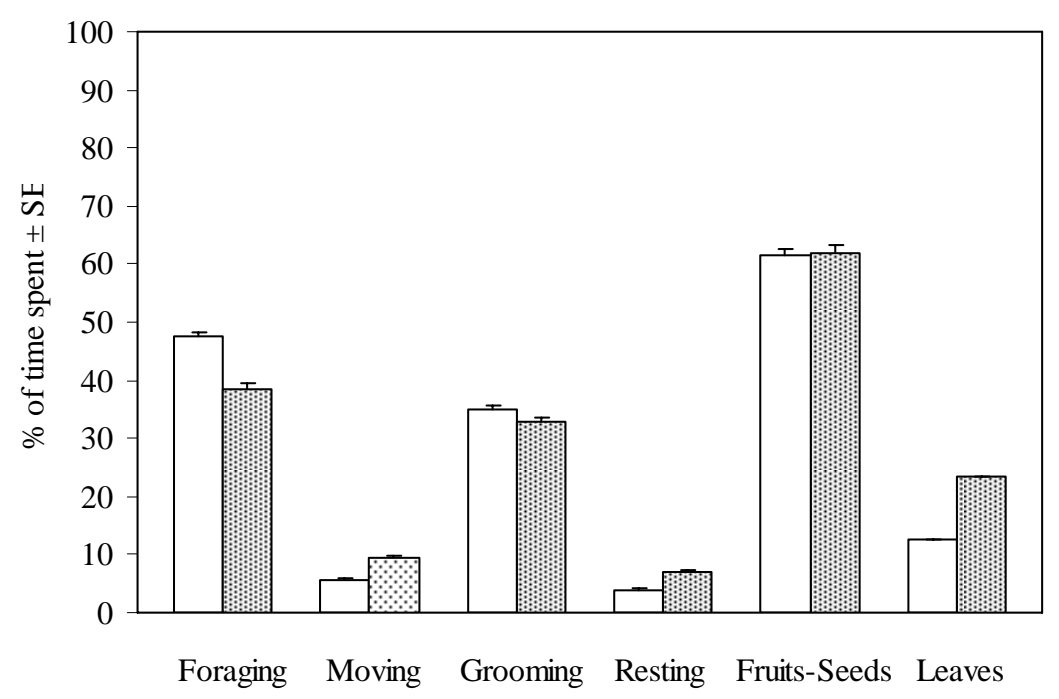




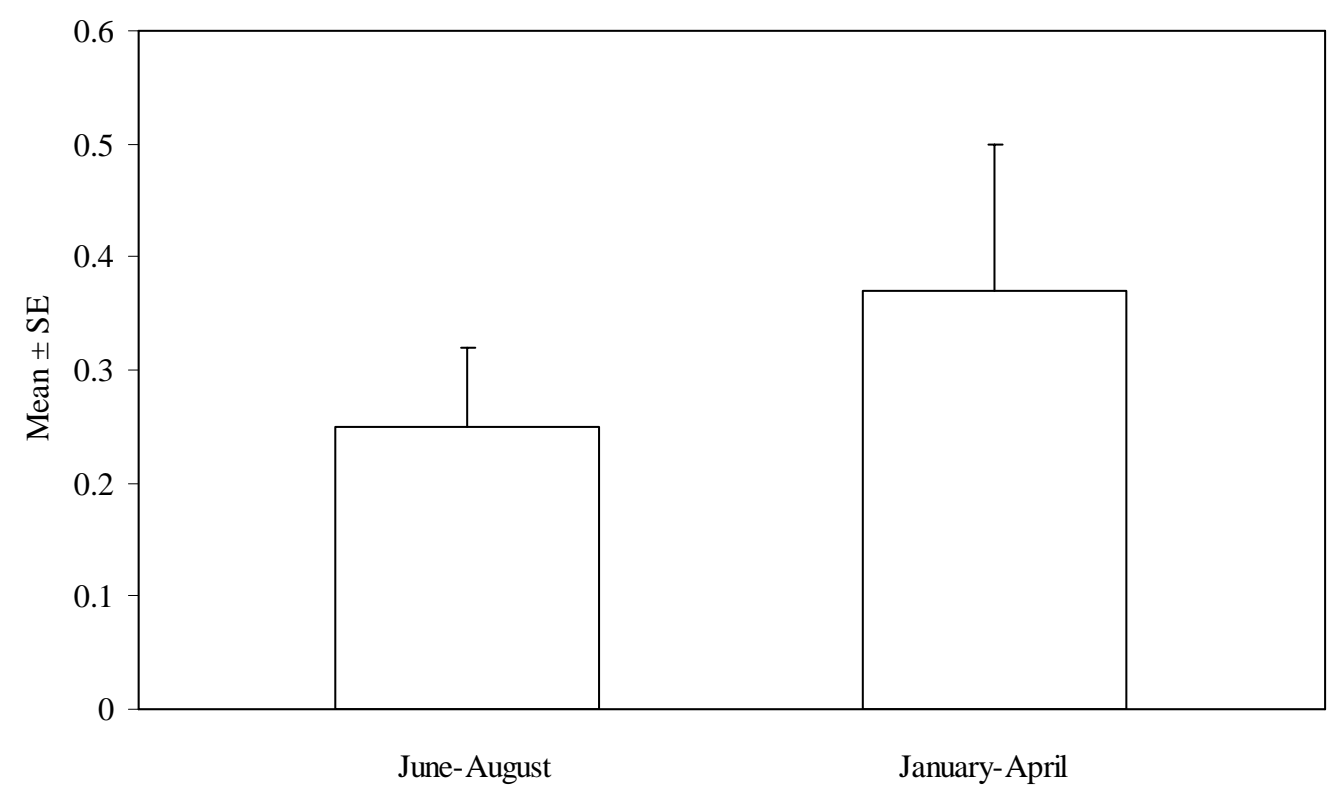




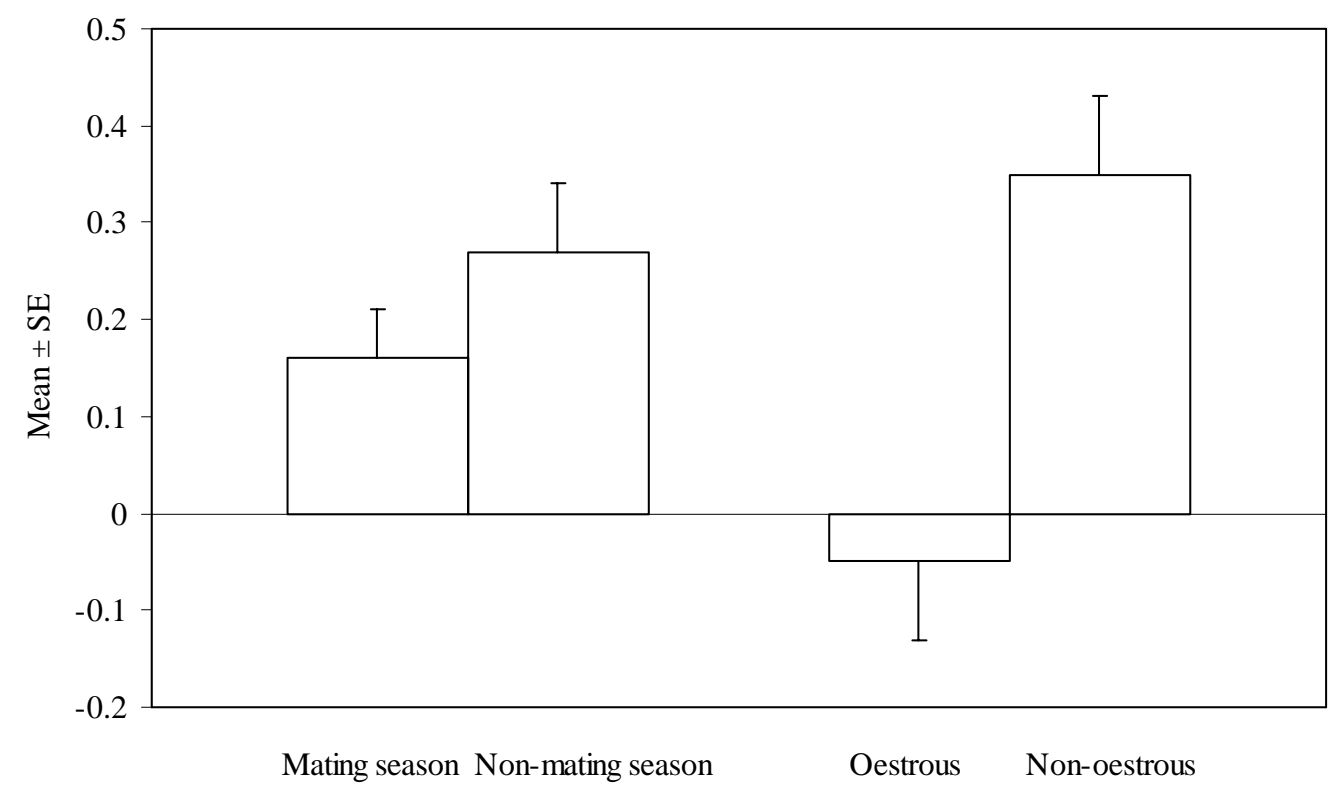

